\title{
الجيل الأول من منظومات التخطيط والمتابعة وتقييم الأداء الحكومي
}

\section{“حصاد عامين على تطبيق نموذج البرامج والأداء في مصر" بتر"}

د.جميل حلمي عبد الو احد"

مقدمة:

خطت الحكومة المصرية خطواتٍ ملموسةٍ وجادةٍ تجاه تطبيق خطة البرامج والأداء، بإعتبارها أحد أهم أدوات التخطيط الاستراتيجي التي يمكن الإستتاد إلبها لتطوير منظومة التخطيط ومن ثم منظومة المتابعة وتقييم الأداء الحكومي، فقطعًا لا يمكن تظوير منظومة المتابعة دون أن يسبقها تبني منهج علمي رصين ومحدد للتخطيط الاستراتيجي. فمع بدء تتفيذ أولويات وبرامج

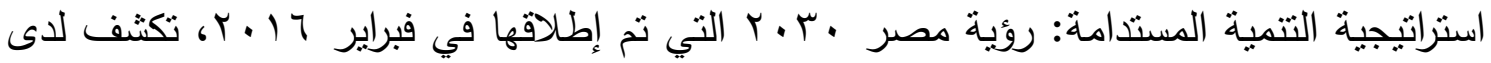
وزارة التخطيط والمتابعة والإصلاح الإداري أهمية البدء في تطبيق برنامج "تطوير منظومتي التخطيط والمتابعة" من خلال تطبيق خطة البرامج والأداء. ومع ضعف نظام المعلومات القومي آنذاك، ظهر تساؤل طالما طرحه مُتخذي القرار يتمحور حول "ماذا تقدم الخطة للمواطن؟"، فلم يكن

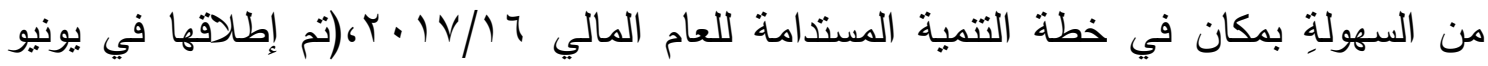

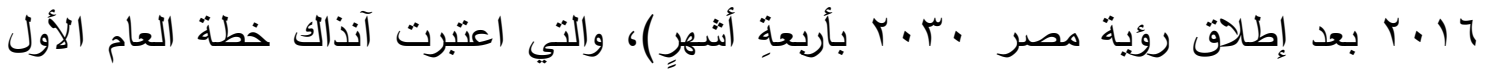
قصيرة المدى من رؤية مصر .r.r.r، أن يتم تحديد مُستهدفات كمية واضحة تتسق مع ما ورد

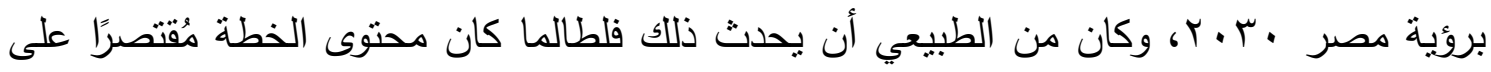
خطة استثارية ومؤشرات أداء مالية فقط، في حين أن تمويل برامج الاستراتيجية لا يقتصر فقط على باب الاستثمارات (الباب السادس من الموازنة العامة للدولة) ولكن من الطبيعي أن يمول من كُل أبوابها، كما أن القانون الحالي المنظم لعملية التخطيط (رقم • V لعام rq I ()) يحدد دور وزارة التخطيط في إعداد الخطة القومية الثاملة التي تقوم على مباديء من بينها مبدأ "شمول الخطة ووحدتها بما يضمن لها استخدام جميع الموارد الوطنية المادية والطبيعية والبشرية"، فضلًا عن ذلك 
نص القانون (المادة (Y) على أحقية وزارة التخطيط في الحصول على كافة البيانات السرية اللازمة لإعداد ومتابعة تتفيذ الخطة. وهنا يجب طرح عدة نساؤلات من بينها، ما المقصود بخطة البرامج والأداء وما أهميتها،

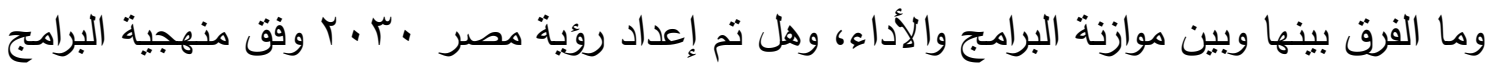

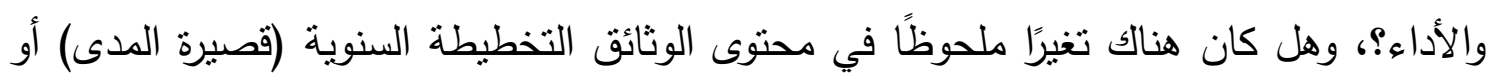

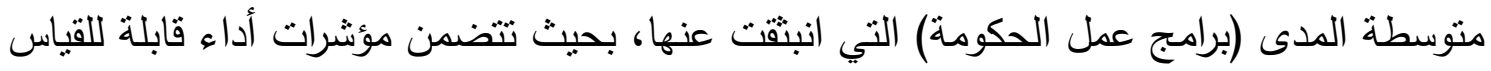
يمكن متابعتها؟ وما هي النجاحات التي تحققت حتى الآن خلال العامين السابقين اللذين تم فيهما

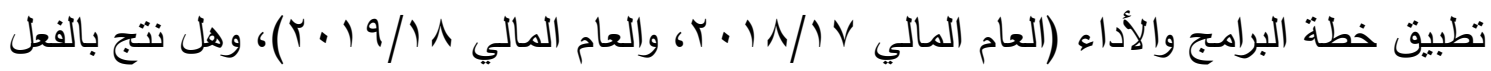

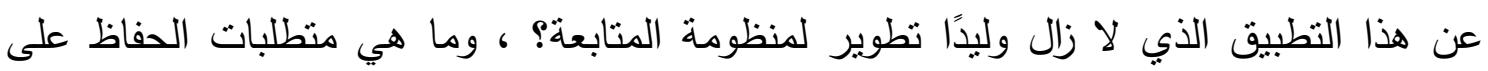

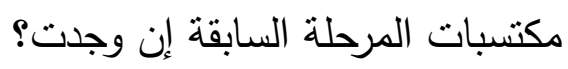
أولاً: المقصود بخطة البرامج والأداء يقصد بخطة البرامج والأداء "رصد الإنفاق العام في خطة التمية المستدامة بالنتائج

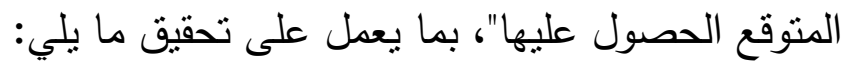
تحسين العلاقة بين عملية التخطيط وجهود التتمية المستدامة على المستوى القومي من خلال التوزيع الأفضل للموارد، والتأكد من كفاءة وفاعلية الإنفاق العام وإعادة ترتيب أولوياته. ت تحسين مستوى الخدمات المقدمة للمواطنين. تحقيق المزيد من الانضباط المالي لكافة أجهزة الدولة عن طريق الرقابة المالية والثفافية

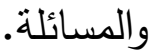

تحقيق الاتساق بين أولويات توزيع الموارد، وتخطيط وإدارة البرامج، وبين استراتيجية التتمية المستدامة: رؤية مصر • ·. ب والاستراتيجيات والخطط القطاعية والمكانية.

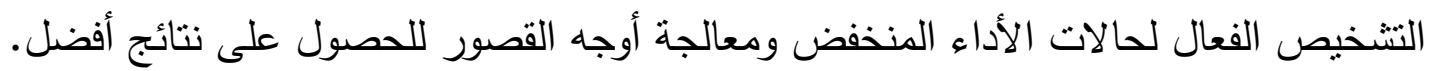
منشر ثقافة التخطيط الاستراتيجي وقياس الأداء في كل أجهزة الدولة. مُساعدة متخذي القرار على إتخاذ قرارات مبنية على معلوماتٍ أفضل. 
• القيام بدورٍ هامٍ في تطبيق ما نص عليه قانون الخدمة المدنية فيما يخص ربط الزيادة في

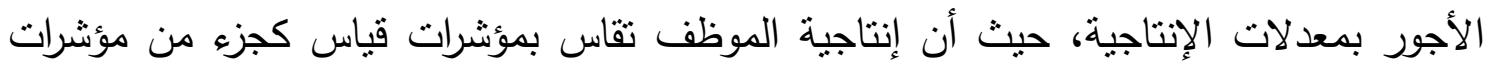
قياس أداء الإدارة والمنوط بها تتفيذ برنامج تتموي له تكلفة ومؤشرات أداء محددة.

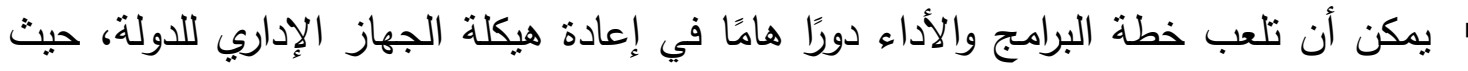

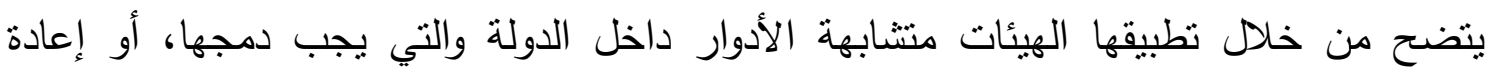
الهيكلة داخل نفس الجهة في حالة وجود أكثر من وحدة تنظيمية تشترك في تتفيذ برنامج تتموي

ثانيًا: الفرق بين خطة البرامج والأداء وموازنة البرامج والأداء في ضوء الممارسات التطبيقية

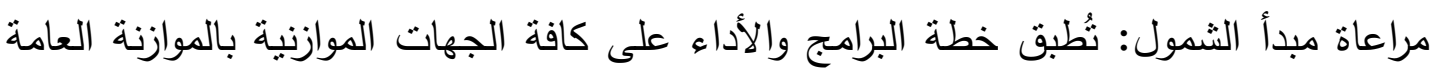

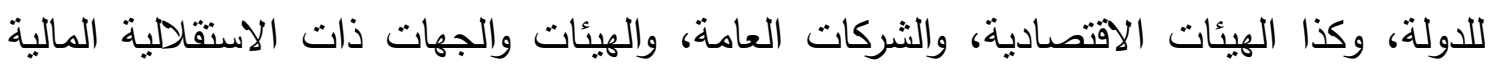
(متل: جهاز تتمية المشروعات المنوسطة والصغيرة ومتتاهية الصغر، وهيئة الرقابة المالية)، وبحيث يتم تصنيف برامج كافة هذه الجهات حسب الأهداف الاستراتيجية التي تتوافق عليها

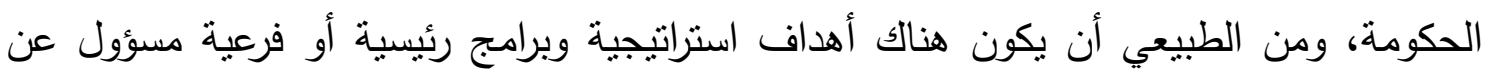
تتفيذها أكثر من وزارة أو جهة (مثال: تتثارك وزارة التتمية المحلية (صندوق التتمية المحلية، و "مشروعك"، وجهاز تتمية المشروعات المتوسطة والصغيرة ومتتاهية الصغر ، ووزارة القوى العاملة في تتفيذ الهدف الاستراتيجي المتعلق بالتشغيل)، ويظل مُحددًا بالخطة مسئولية كُل منها بمفردها

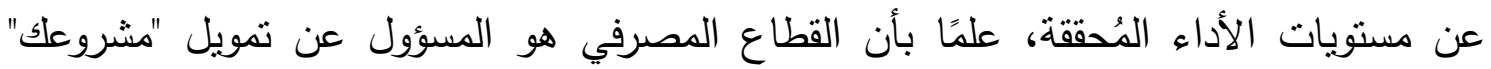

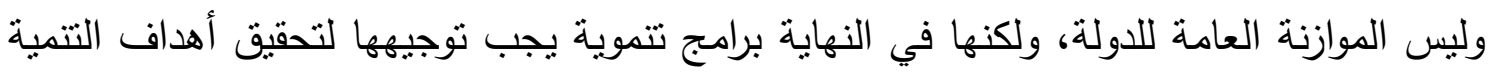

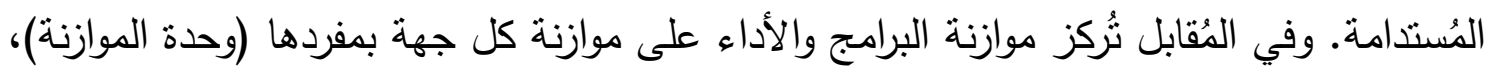

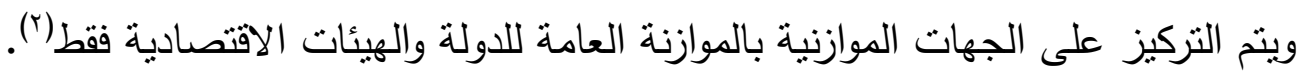

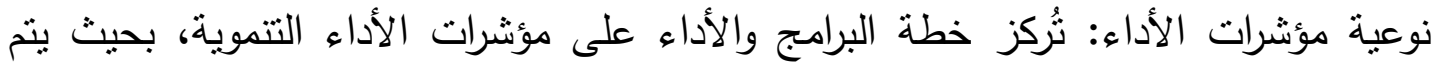

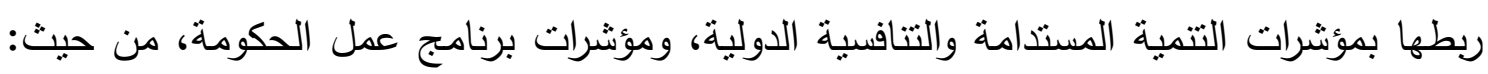


دقة التخطيط المالي (المُدخلات المالية والبشرية)، والمُخرجات، والأثز، في حين ثُركز موازنة البرامج والأداء على مؤشرات الأداء المالية بشكلٍ أساسي.

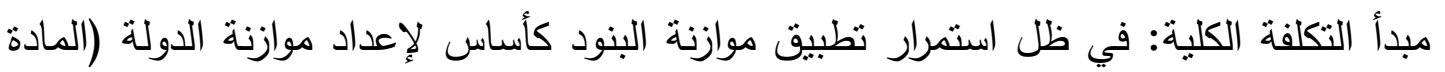
رقم § I من الدستورالمصري تتص على أن "تثمل الموازنة العامة للدولة كافة إيراداتها

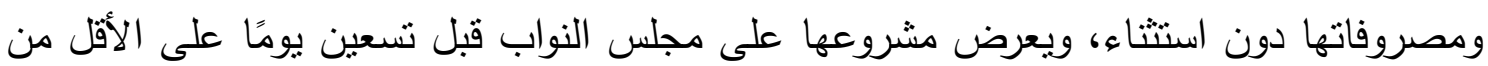

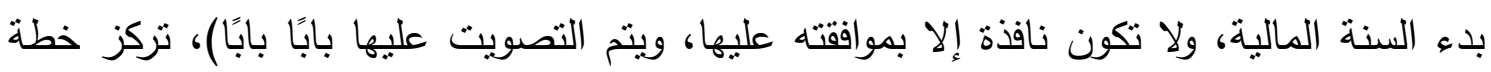
البرامج والأداء على تتبع عائد إنفاق بند التكلفة الذب يستحوذ على إلى النسبة الأكبر من موازنة كل

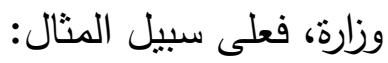
- تُعد وزارتا "الإسكان والمرافق والمجتمعات العمرانية، والاتصالات وتكنولوجيا المعلومات" من

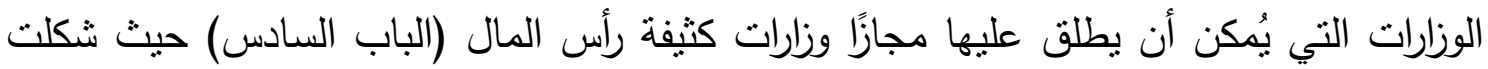

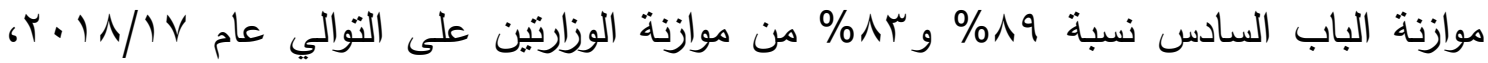
وبالتالي فإن خطة البرامج والأداء ثُركز على عائد الاستثمار العام (حكومة، هيئات اقتصادية لهادية، شركات عامة) لهذا النوع من الوزارات بشكل أساسي، وبالتالي يجب أن يتم التركيز على مؤشرات الأنيات

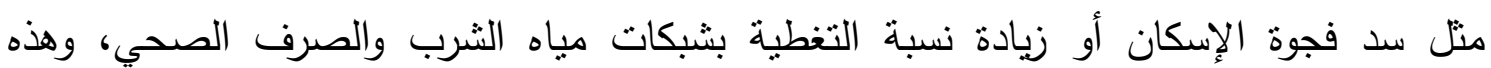

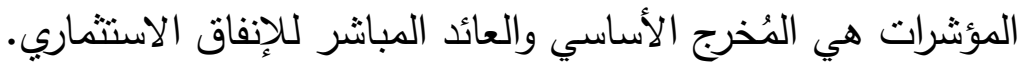

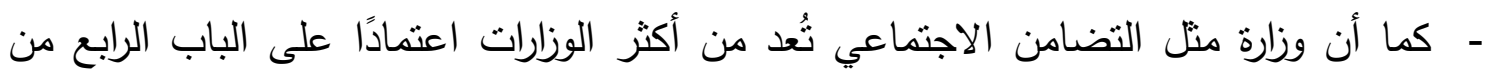

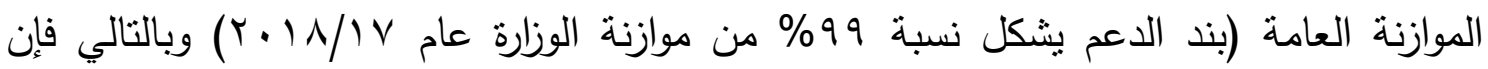

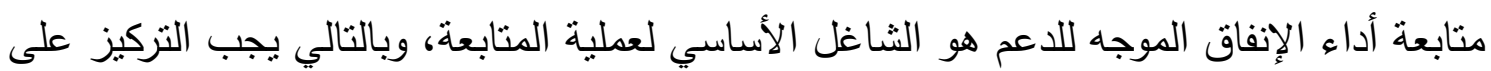

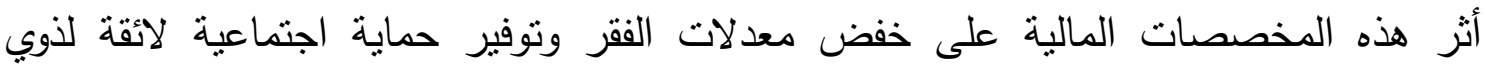

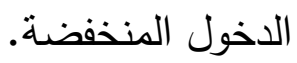
- بينما تُعد وزارة الثربية والتعليم من الوزارات كثيفة الأجور، حيث بستحوذ بند الأجور على نسبة

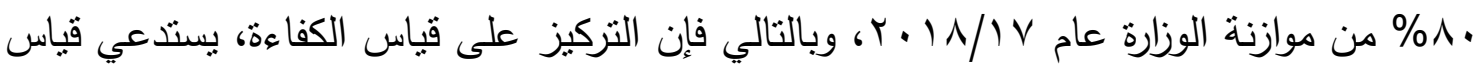
أثنز هذه المُخصصات المالية بالأساس على جودة خدمة التعليم وأداء المعلمين. 


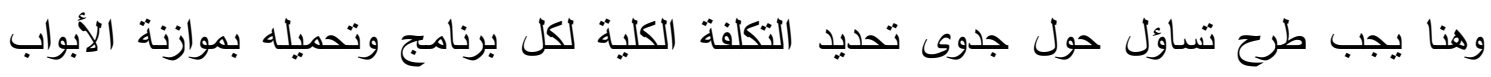

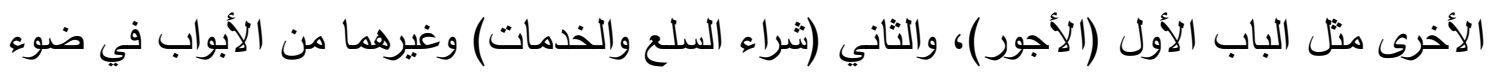
صعوبة تقسيم مخصصات هذه الأبواب على كافة البرامج المنوط بكل وزارة تنفيذها. وبالثالي فإن الناب التابل

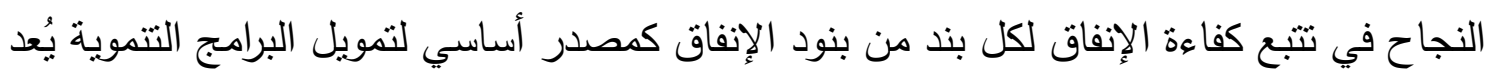
الأساس المنطقي الذي تركز علية وزارة التخطيط والمتابعة والإصلاح الإداري.

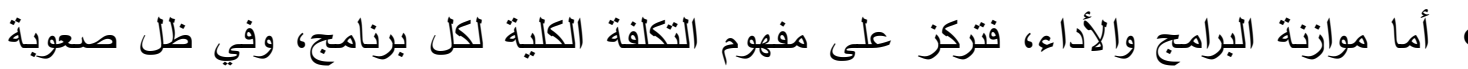

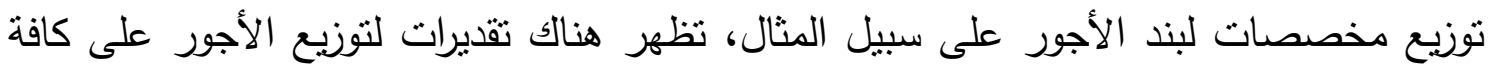

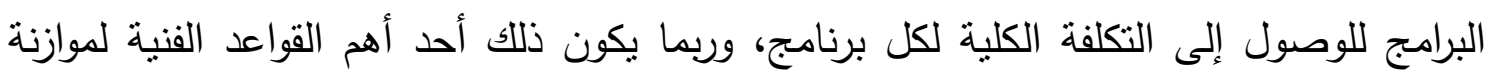
البرامج والأداء، ولكن في ظل الاستمرار في تطبيق موازنة البنود كأساس لعملية الموازنة العامة.

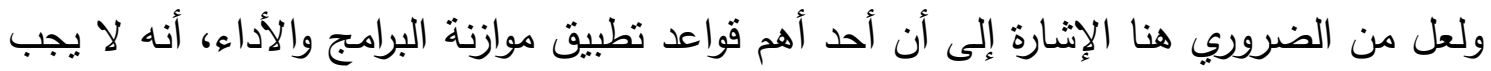

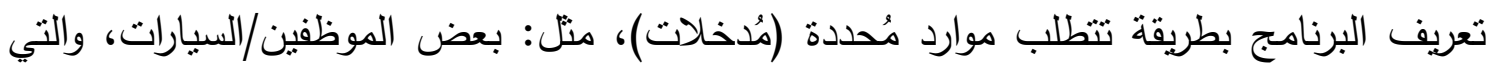
تتوزع بين البرامج، إلا إذا كان هنالك قدرة على تسجيل استخدام هذه الموارد المشتركة في كل

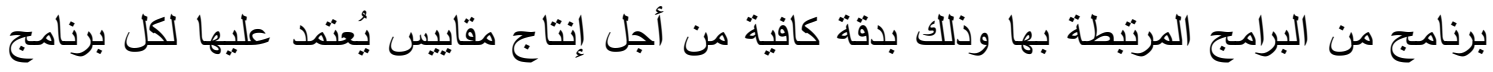

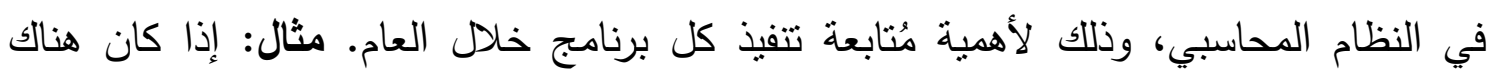

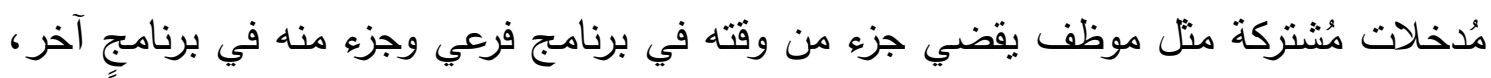

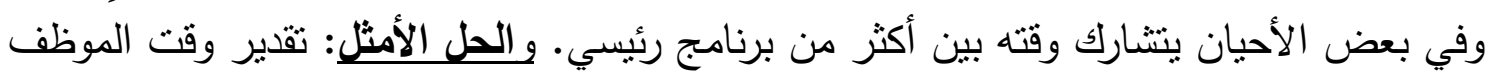

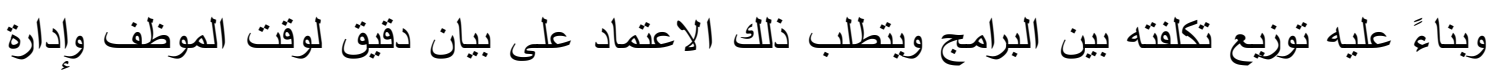

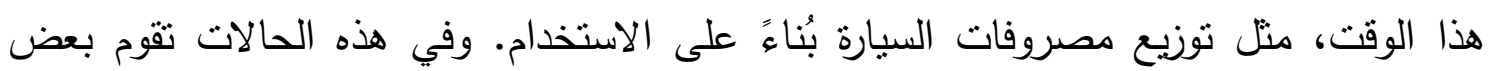
الوزارات بتبسيط الفروض، منل: نوزيع تكلفة الموظفين بالتساوي بين البرامج الفرعية، ولكن النتيجة النهائية للتكلفة تكون غير موثوق فيها. مثال عملي: قامت الثرطة الاسترالية بتطوير برنامج عن الثرطة التفاعلية وبرنامج للثرطة Time Record الاستباقية، وكان كُل الضباط منخرطين في تتفيذ البرنامجين، وكان لابد من التنجيل بواسطة الضباط ومراجعة من قبل رؤسائهم. الحل: وجدت وزارة الداخلية أنه لا يتم تسجيل الوقت بدقه، وقررت عمل Survey لقياس الوقت الذي بستغرقه كل ضباط خلال ب شهور ومن ثم الاعتماد 
على ذللك كأساس مُحاسبي. ومن هنا وفي ظل المراحل الأولى من تطبيق موازنة البرامج والأداء فإنه من الصعوبة بمكان تطبيق منل هذه الحلول المحاسبية الدقيقة للوصول إلى تكلفة كلية دقيقة.

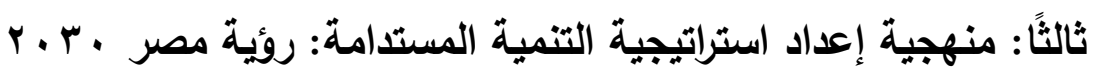

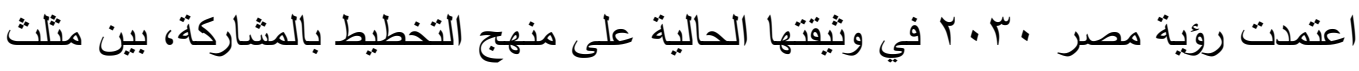
التتمية "الحكومة، القطاع الخاص، المجتمع المدني" فضلاً عن مشاركة فاعلة من خبراء وأكاديميين ومراكز فكر وبحث علمي. ولا يمكن تجاهل أهية ما أحدثته الاستراتيجية من تحول جوهري تجاه

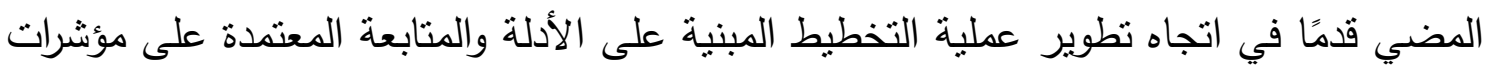

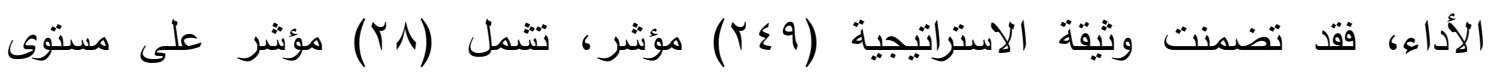

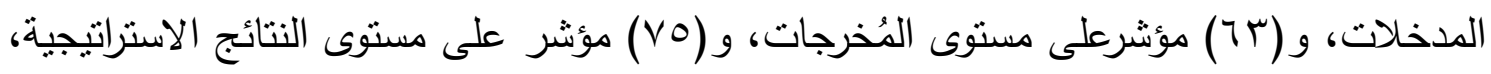

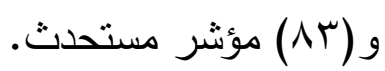
وبالرغم من ذلك، إلا أن وثيقة الاستراتيجية (في كافة محاورها)، لم تراع ما يلي: ه تضمين تكلفة تقديرية لما نصت عليه من برامج ولا مصادر التمويل الممكنة (خزانة عامة،

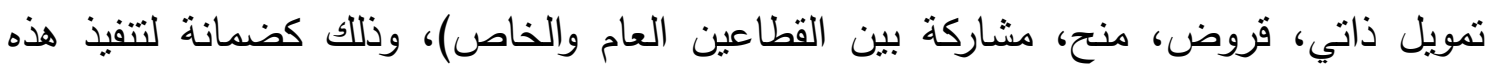

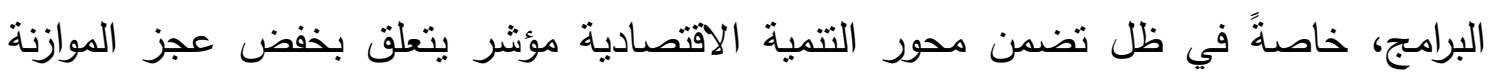

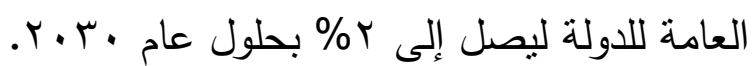
• اقتصر الأمر (في مقدمة الاستراتيجية) على تحديد "تحديات التمويل" كأحد أهم التحديات التي

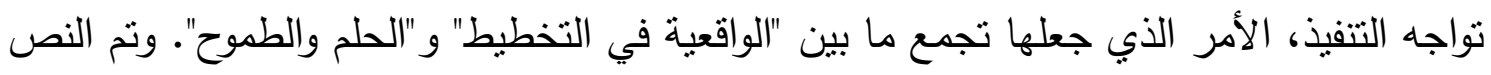

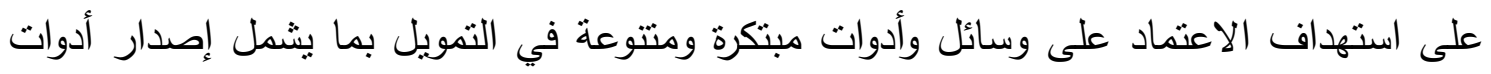

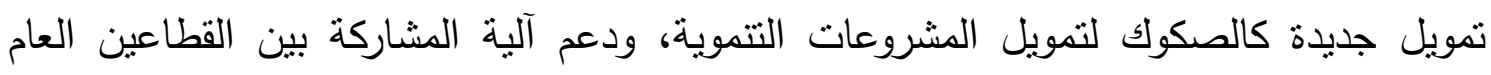

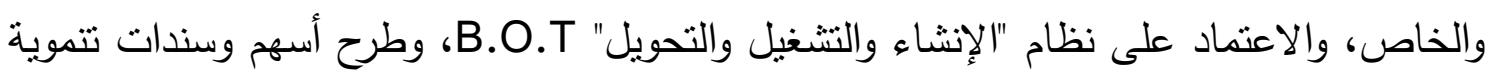

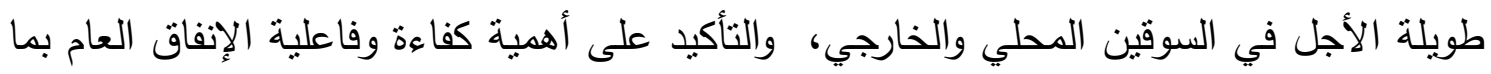

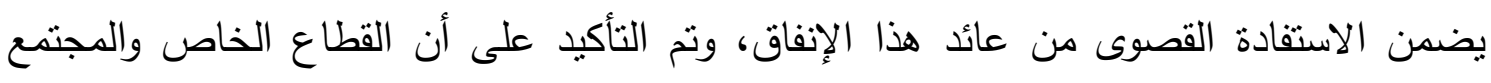

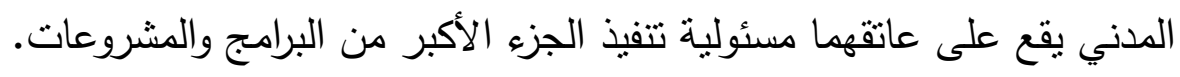


تضمن كل محور من محاور الاستراتيجية "رؤية، وأهدافًا استراتيجية، ومؤشرات قياس أداء"،

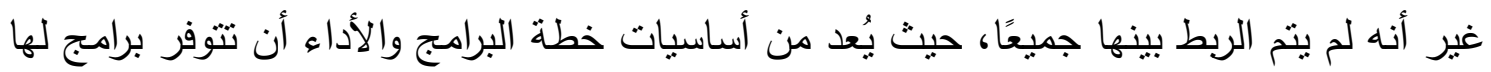

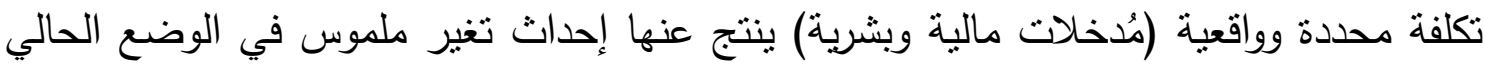

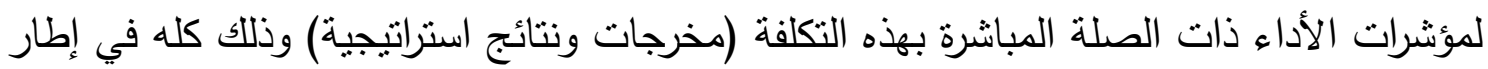
منطقي مترابط ومتجانس يضمن تحقيق الهدف الاستراتيجي، دون الحاجة للبحث عن طريقة

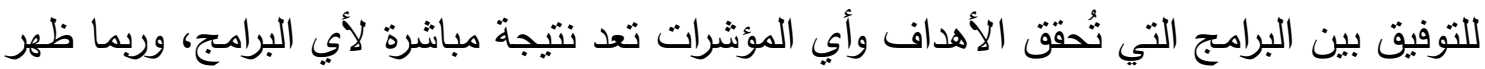
ذللك بشكلٍ واضح أثناء عملية المتابعة.

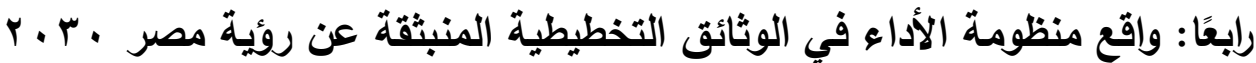

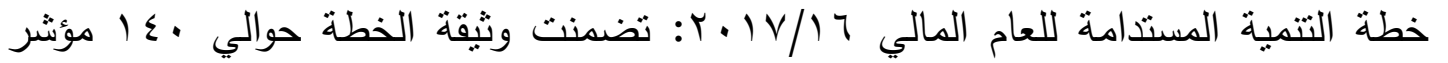
أداء غير مالي. كما تضمن ملحق الخطة توضيح لآلية المتابعة التي تستهدف رفع كفاءة الإنفاق العام وتحسين جودة حياة المواطنين بهذف تحقيق أهداف التتمية المستدامة، كما تضمنت مجموعة

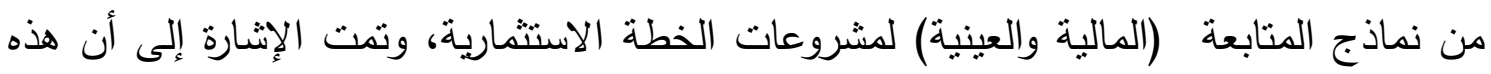
خطوة في طريق بناء منظومة مؤشرات قياس الأداء على مستوى المدخلات والمخرجات والنتائج.

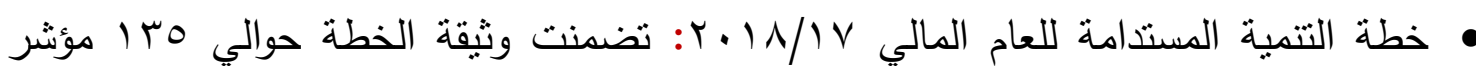

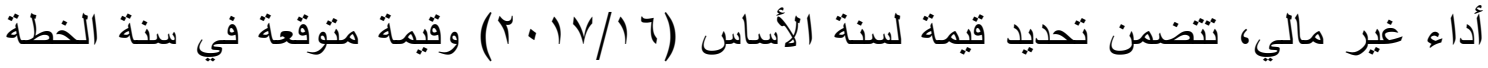

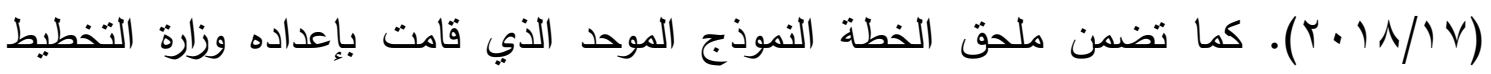

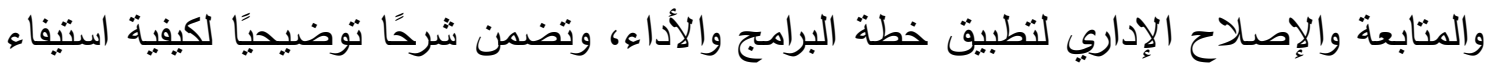

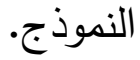

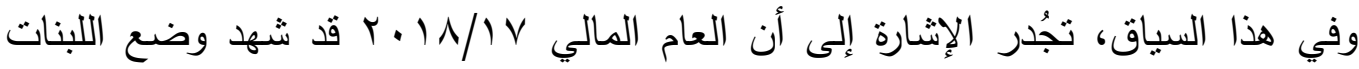

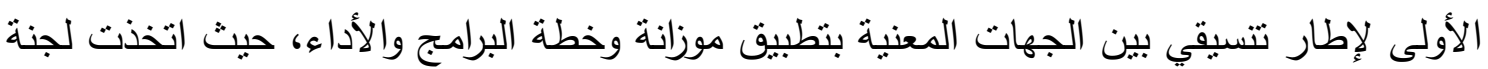

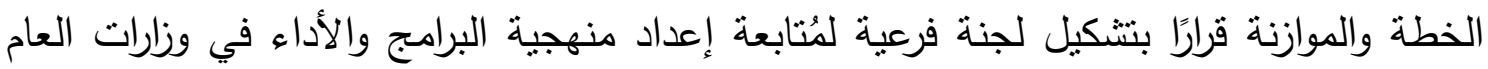

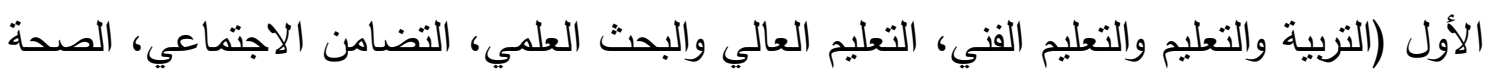
والسكان، الاتصالات وتكنولوجيا المعلومات، الإسكان والمرافق والمجتمعات العمرانية، النقل)، بحيث تُضم اللجنة مُمنلين لوزارتي المالية والتخطيط فضلاً عن ممثلي الوزارات المعنية بالتطبيق. 
وذلك بهدف مُتابعة مراحل التحول ومدى التزام الوزارات المعنية بالتطبيق. وقد خلُصت الإجتماعات التي تم تتظيمها آنذاك حول هذا الثأن إلى ما يلي: - مضع إطار نوافقي مع الأطراف المعنية لإدارة مرحلة الإنتقال لموازنة البرامج والأداء. - الاتفاق على حتمية العمل على تطبيق موازنة البرامج والأداء.

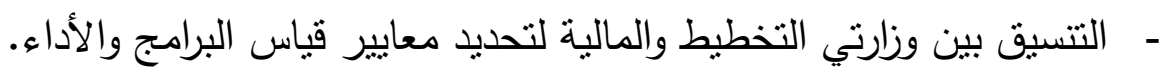

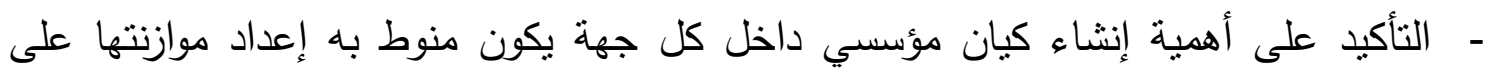
أساس موازنة البرامج والأداء. - أهمية إعداد وتدريب موظفين مؤهلين علميًا وعمليًا لإدارة وتتفيذ هذا النوع من موازنات البرامج والأداء.

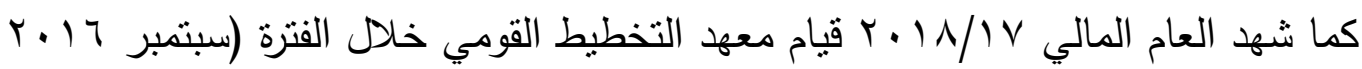

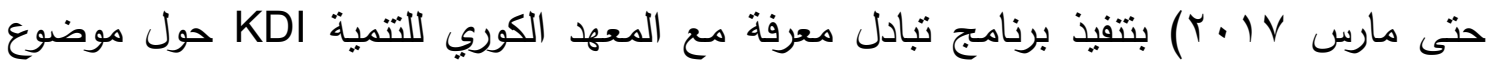

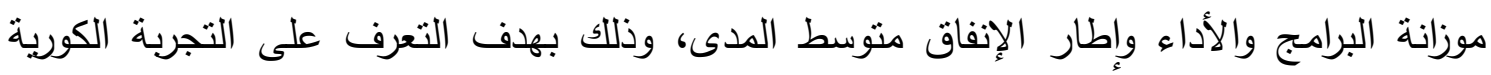

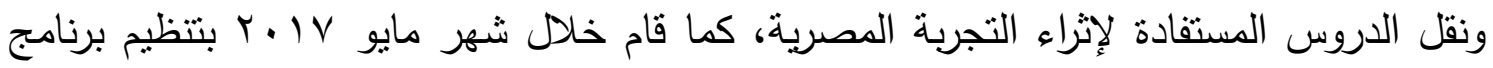

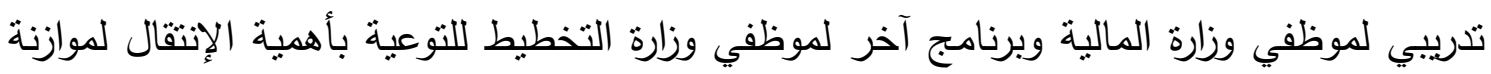

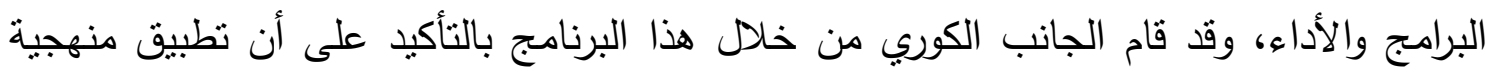

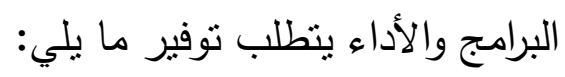

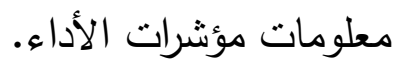

• معلومات حول التكلفة المعيارية للمشروعات. • الحصول على بعض المعلومات حول الأداء والتكلفة لبعض البرامج وتطبيق موازنة البرامج عليها. ه دراسات جدوى تفصيلية ودقيقة للمشروعات. توفير توقعات للمؤشرات الاقتصادية.

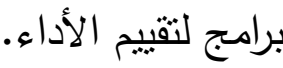
ق قاعدة بيانات لأصول الدولة. 


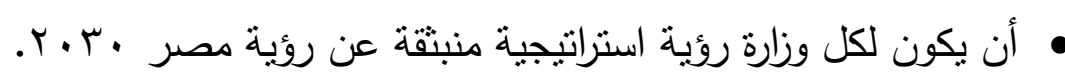
ت تسهيل التواصل بين الوزارات المختلفة.

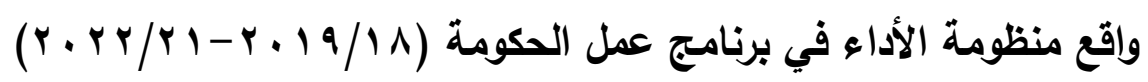

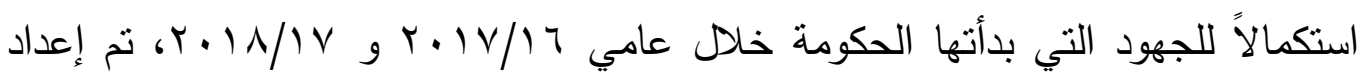

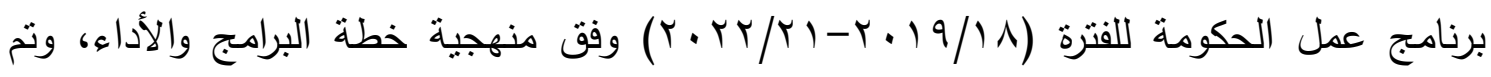

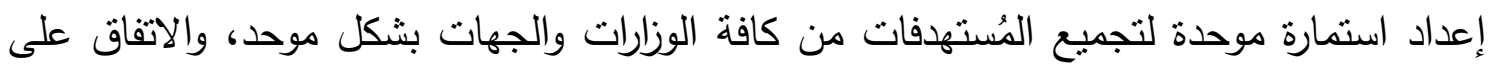

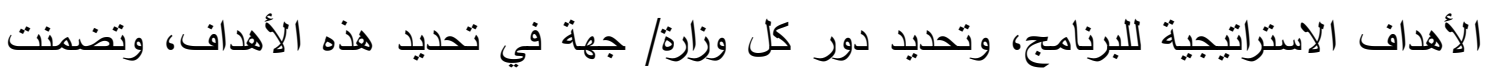

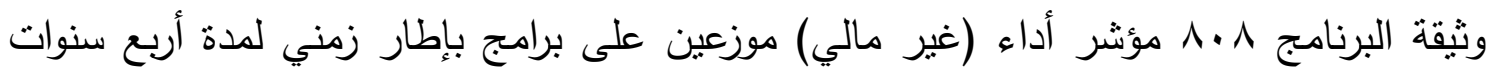

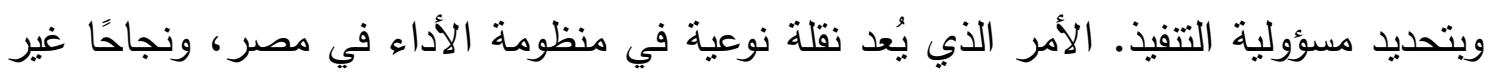

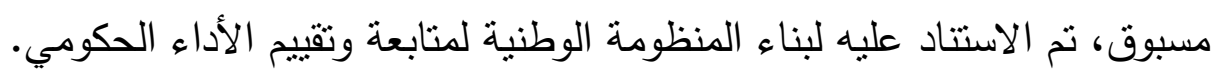

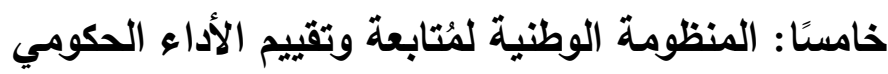

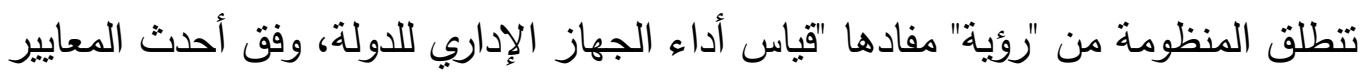
العالمية، للوصول إلى أداء حكومي متميز".

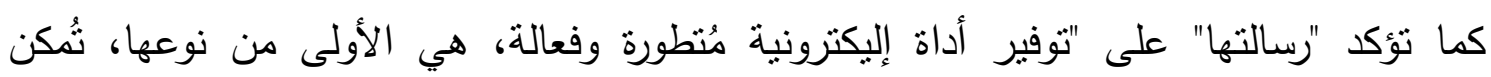

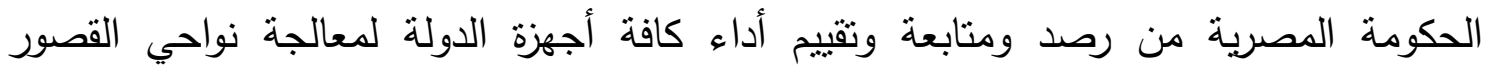
بإجراءات تدخل عاجلة، وترتبط بالموازنة العامة للاولة بما يضمن كفاءة تخصيص المباء الموارد، وتكون

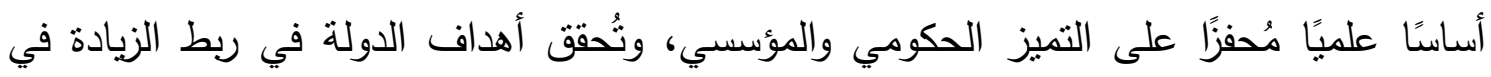
أجور العاملين بمستويات الإنتاجية".

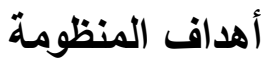

ضمان تتفيذ المستهدفات التتموية التي توافقت عليها الحكومة. • تحقيق أكبر قدر من التسسيق بين الوزارات والجهات المختلفة. تصليط الضوء على حجم الإنجازات التي تقوم بها الدولة.

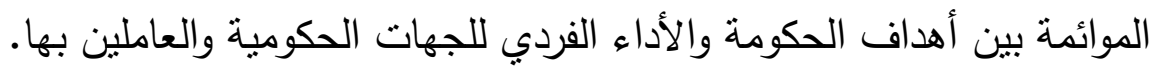
تحسين جودة الخدمات المقدمة للمواطنين. 
• ضمان تحقيق كفاءة وفاعلية الإنفاق العام.

قياس أثز البرامج التتموية التي تتفذها الحكومة على تحقق أهداف التتمية المستثامة.

•إيجاد حلول عاجلة للمعوقات، ومن ثم تقويم الأداء، ضمانًا لتنفيذ المستهدفات.

مأسسة التخطيط الاستراتيجي وقياس الأداء داخل الجهاز الإداري للاولة.

تعزيز قُدرات العاملين بالجهاز الإداري للدولة في مجال خطط البرامج والأداء.

\section{المراحل الأساسية للمنظومة}

المرحلة الأولى: مرحلة التخطيط: تم إعداد خطة عمل تتفيذية ربع سنوية لعام ^/9 1 ـ ب لكافة

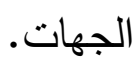

• المرحلة الثانية: مرحلة المتابعة: استلام نماذج المتابعة من كافة الجهات بشكل ربع سنوي،

والتحقق منها، قبل إدخالها على منظومة المتابعة. • المرحلة الثالثة: مرحلة التقييم: تقوم المنظومة بتقييم الأداء بشكل تلقائي، بُمقارنًة القيمة المنفذة في كل مؤشر أداء مع القيمة المُّتهدفة في ذات الفترة.

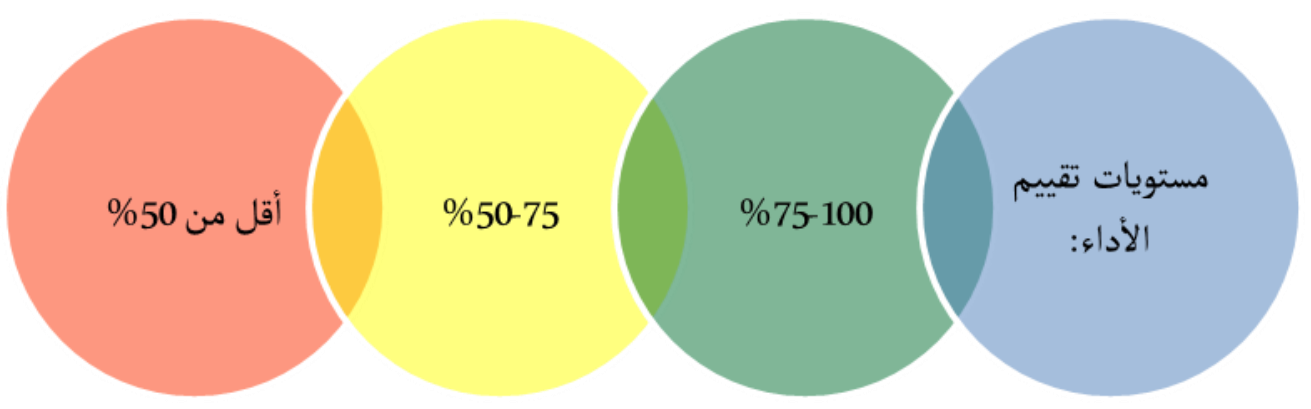

منهجية التحقُق من بيانات المُتابعة • بتم استلام بيانات المتابعة من كل وزارة مُوقعة من الوزير المختص. فقوم فريق المتابعة بوزارة التخطيط والمتابعة والإصلاح الإداري بمُراجعة البيانات، وإعداد تقرير فني يتضمن أهم الملاحظات الواجب مُراعاتها. تتظيم ورش عمل لمناقشة كافة مؤشرات الأداء مع فرق المتابعة بالوزارت والجهات المعنية. 
• يتم طلب تفاصيل عن كل مؤشر فيما يخص وصف الإنجاز النوعي، والتوزيع الجغرافي. • إرسال تقارير الأداء للجهات الرقابية للمعاونة في التحقُق من كل مؤشرات الأداء.

مُخرجات منظومة الأداء

• تقربر ربع سنوي يتضمن تقييم أداء كل وزارة، يوضح المؤشرات ذات الأداء المُرتقع والمتوسط والمنخفض.

• تقربر ربع سنوي بعنوان "حصاد مرحلة البناء في .9 بوم" يتضمن توثيقًا شاملاً لكافة المشروعات الاستثارية التي تم الانتهاء من تتفيذها كل ربع سنة، ويتضمن بيانات عن أهمية كل مشروع، وتكلفته الكُلية، وموقعه الجغرافي، وتاريخ البدء والانتهاء من تتفيذه، وصور للمشروع. • تقرير دوري عن المعوقات التي تحول دون تتفيذ المستهدفات التتموية. الإطار المنطقي لمنظومة المتابعة وتقييم الأداء

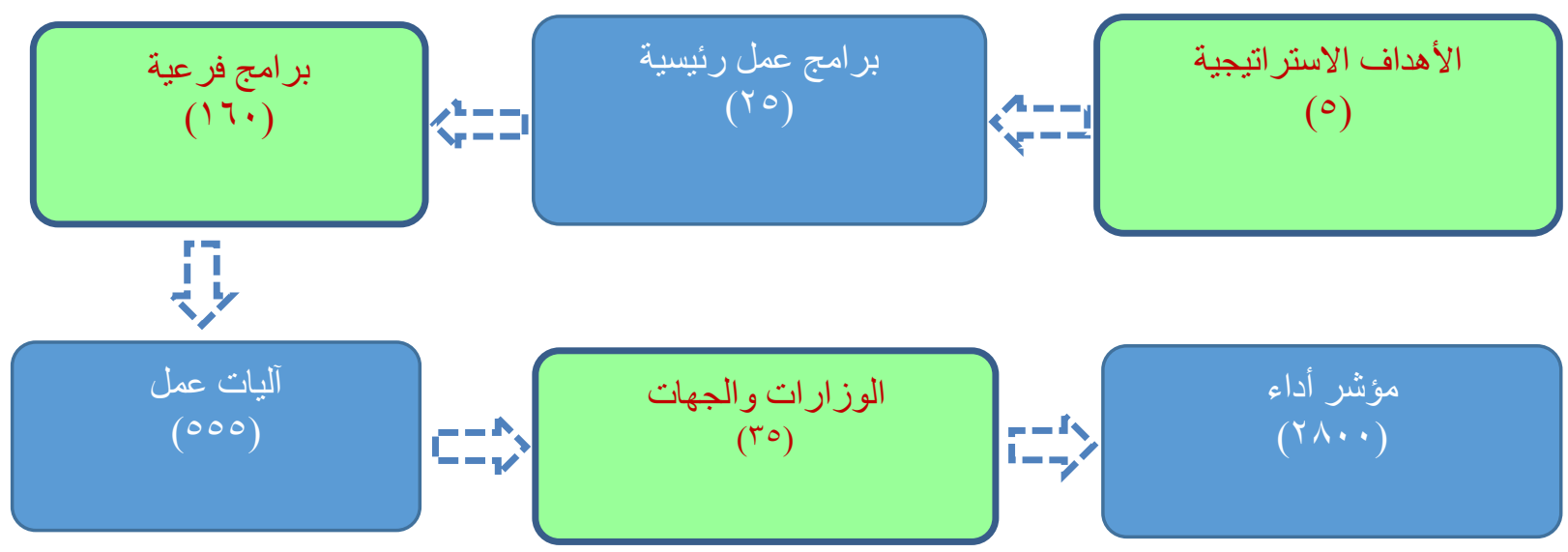

سادسًا: العوامل الداعمة لنجاح موازنة البرامج والأداء خلال القترة الحالية الاهتمام البالغ من الحكومة بأهمية تضمن برنامجها مؤشرات أداء قابلة للقياس، وكذا تقارير المتابعة المقدمة لمجلس النواب (نصف سنوية). الدعم المقدم والمتابعة الدورية من لجنة الخطة والموازنة بمجلس النواب (اللجنة الفرعية لموازنة

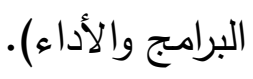


اهتمام وزارة التخطيط والمتابعة والإصلاح الإداري بإعداد نماذج تخطيطية لتوحيد عملية إعداد موازنة البرامج والأداء بين كافة الوزارات والجهات، وتطوير هذه النماذج بشكل مستمر في ضوء النضج المتحقق خلال الممارسة النطبيقية. تشكيل فرق عمل داخل الوزارات برئاسة نائب أو مساعد الوزير للإثراف على متابعة تتفيذ برنامج عمل الحكومة، وتُعد هذه الفرق نواة لوحدتي "التخطيط الاستراتيجي والسياسات، والمتابعة والتقبيم"، والجاري تشكيلهما داخل كل وزارة حاليًا. يعتبر صدور قانون الخدمة المدنية من العوامل الداعمة والمشجعة على الانتقال لمنهجية البرامج والأداء، وذلك لأنه خطوة هامة في طريق ربط الأجر بتقييم الأداء الوظيفي ومعدلات الإنتاجية. في إطار أهمية مواكبة التطورات العالمية الحديثة في التخطيط الاستراتيجي، تم إعداد قانون جديد للتخطيط العام، وجاري مناقنة القانون بمجلس النواب، وبعد صدور القانون، سيكون المجال مناسبًا لتضمن اللائحة التتفيذية نصوصًا تؤكد على أهمية تطبيق خطة البرامج والأداء وتقديم الخطة وفق استمارات محددة ثُراعي ذلك. • تُعد المنظومة الوطنية لمتابعة وتقييم الأداء الحكومي "الجيل الأول" في منظومات متابعة وتقييم الأداء في مصر، حيث توفر نظام المعلومات الذي كان مطلوبًا لتهيئة المناخ لتطبيق فاعل وجاد لخطة البرامج والأداء. إنشاء وحدة لخطة البرامج والأداء بوزارة التخطيط والمتابعة والإصلاح الإداري، بهدف القيام بما يلي: - - وضع الأدلة الإرشادية والنماذج والأطر المنطقية لإعداد خطط وموازنات البرامج والأداء التي يجب على كافة جهات الإسناد الاستعانة بها والإلتزام الدقيق بها عند إعداد خطط وموازنات البرامج والأداء. - تحديد البرامج التتموية (الرئيسية والفرعية) التي يجب أن تتضمنها الخطط المقدمة من كافة جهات الإسناد (جهاز حكومي، هيئات اقتصادية، شركات عامة، محافظات)، والمستهدفات الكمية (مؤشرات الأداء على مستوى المخرجات والنتائج والأثر) الخاصة بكل برنامج تتموي، وذلك اتساقًا 


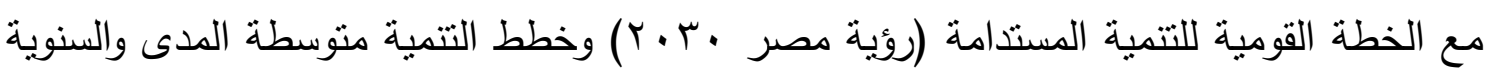
المنبثقة عنها. - - تقدير التكلفة الكلية لتتفيذ كل برنامج تتموي (من كافة الأبواب)، وذلك بالتثاور والتتسيق مع كافة جهات الإسناد والأطراف ذات الصلة. - تحديد المشروعات الاستثمارية لكل برنامج تتموي، وتحديد تكلفته (الباب السادس).

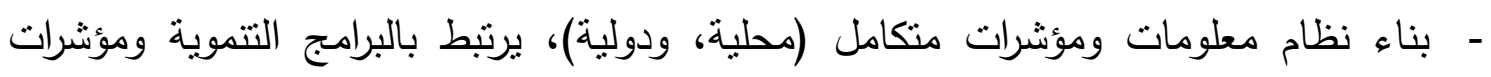

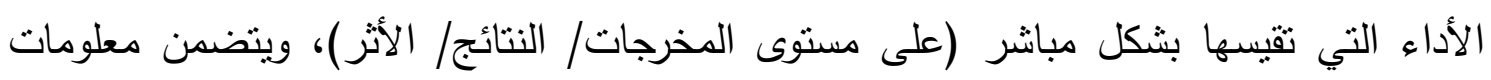

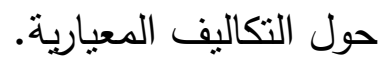
- إعداد تقارير المتابعة الدورية (ربع سنوية، سنوية) لرصد وتقويم مستوى الإنجاز المحقق في كافة البرامج التتموية. - إعداد والإثراف على تتفيذ خطة لبناء وتتمية قدرات المسؤولين عن إعداد خطط وموازنات البرامج والأداء بكافة الوزارات. سابعاً: مُنطلبات تطوير آليات تطبيق خطط البراء بكاتهج والأداء

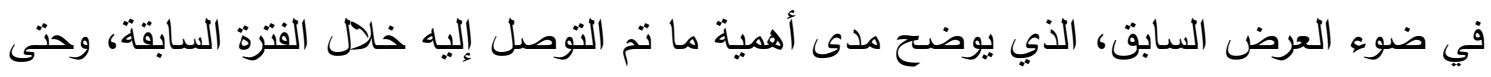

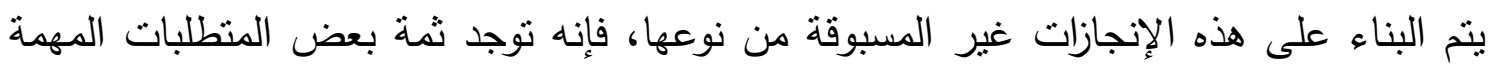

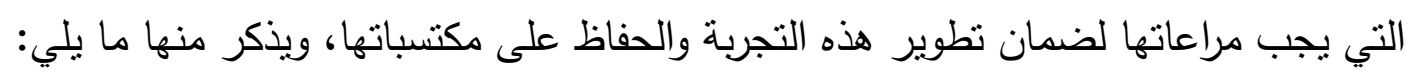

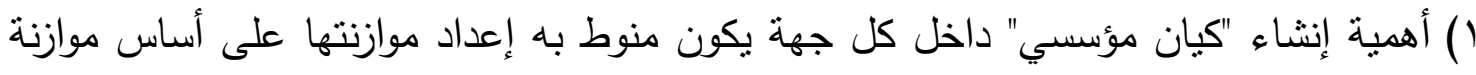
البرامج والأداء، ويُقترح في هذا الصدد نتشكيل فريق عمل يضم ممنلين عن وحدات "الموازنة

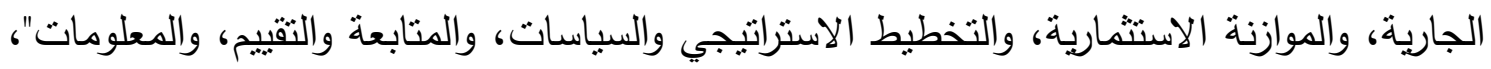

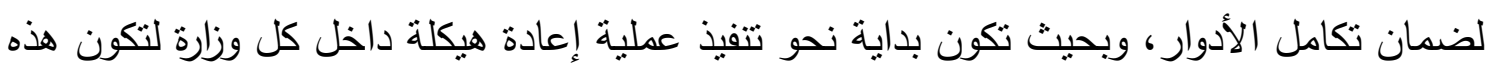
الوحدات تحت مظلة وحدة تتظيمية واحدة. r) وضع خطة "بناء قدرات" فرق العمل التي يتم تتكيلها (والتأكيد على عدم تغييرها)، لإيجاد كفاءات إدارية قادرة على تتفيذ منطلبات خطط البرامج والأداء. 
ب) توفير المعلومات عن "تكلفة الوحدة الواحدة" Unit Cost من المخرجات واستخدامها في إعداد خطط البرامج والأداء، وتقوية العلاقة بين نظم المعلومات وعمليات إتخاذ القرار . ع) دمج "أولويات الإنفاق وأداء البرامج" في عملية إعداد الخطة وتوزيع المخصصات المالية بإستخدام مؤشرات قياس الأداء.

0) مرونة "العمليات الإدارية" من خلال تخفيض عدد الموظفين في البرامج ذات الأولوية المنخفضة أو البرامج غير الفعالة، وإعادة توزيعها على البرامج ذات الأولوية.

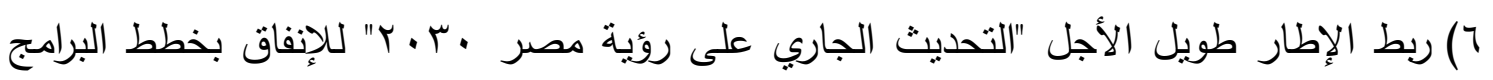
والأداء وبما يحسن من مستوى الثفافية وتحديد أولويات الإنفاق. V) تقوية "العلاقة بين مؤشرات الأداء" التفصيلية (Micro) التي تنتهدفها الجهات الحكومية

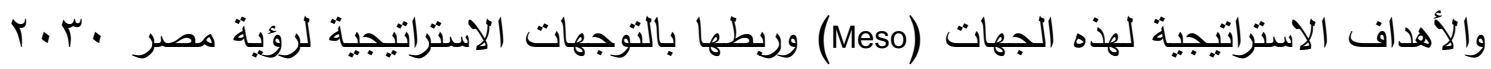
-(Macro) ^) إن بناء وتأسيس نظام خطط البرامج والأداء يعد "عملية سياسية أكثر منها عملية فنية"، فحتى مع وجود جميع المُنطلبات الفنية لا غنى عن وجود الدعم السياسي، وهو ما يتوفر في المرحلة الحالية بشكلٍ واضح (الحكومة، البرلمان، تعاون فرق العمل داخل الوزارات والرغبة في التغيير والتطوير). 9) يحتاج تطبيق خطط البرامج والأداء إلى "إطار تشريعي مساند وداعم"، وفي هذا الإطار سوف يكون قانون التخطيط العام داعمًا لذلك، كما أن هنالك تعديل جاري تتفيذه على قانون إعداد الموازنة ليتضمن بنودًا ملزمة في هذا الثأن. • () ضرورة خلق الوعي والتوعية بمفاهيم الأداء والنتائج وضرورة الإصدلاح المالي وموازنات الأداء، من خلال ورش عمل وجلسات عصف ذهني، وذلك حتى يمكن خلق نقافة الأداء، وفي هذا السياق قامت وزارة التخطيط خلال النصف الأول من عام 19/1 1 ـ ب بتتظيم 00 ورشة عمل تدريبية مع الجهات المعنية استفاد منها ربr موظف، و ع حلقات نقاشية استفاد منها ماب موظف. 
1)"توفر معلومات الأداء"، وضرورة أن نكون كل طلبات الوزارات للتمويل مدعومة ببيانات عن كفاءة وفعالية الإنفاق الخاص بها، وهو ما تم تداركه بشكل جوهري خلال العامين الماضبين، غير أنه يجب أن يتم توزيع المخصصات المالية باستهداف تحقيق مؤشرات التتمية المستدامة Prospective وليس كنتيجة لهذا التوزيع Retrospective ץ ( )تطوير “الهياكل التظيمية” للجهاز الداري للدولة لأهمية تحديد الوحدات التظيمية المسؤولة عن تتفيذ كل برنامج. ب ( )ضرورة التركيز على “الحوافز الصريحة والضمنية” التي تشجع المديرين والعاملين في الحكومة والقطاع العام على التركيز على النتائج وتحقيق الأهداف واستخدام معلومات الأداء والاهتمام بجودتها وصلاحيتها. 